ISSN 2620-6760, Vol. 2, No. 1, Oktober 2018

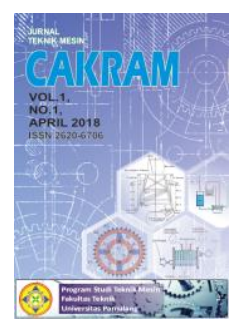

\title{
CAKRAM
}

\section{RANCANG BANGUN DESTILATOR AIR LAUT SKALA RUMAH TANGGA UNTUK DAERAH PESISIR}

\author{
Joko Setiyono ${ }^{1}$, Nailul 'Atifah ${ }^{2}$, Ihat Solihat ${ }^{3}$ \\ ${ }^{1,2,3}$ Program Studi Teknik Mesin, Universitas Pamulang, Jl. Surya Kencana No. 1, Tangerang Selatan, Indonesia \\ E-mail : dosen00889@unpam.ac.id ${ }^{1}$, dosen00410@unpam.ac.id ${ }^{2}$, dosen00990@unpam.ac.id ${ }^{3}$
}

Masuk : 21 Juni 2018

Direvisi : 27 September 2018

Disetujui : 2 Oktober 2018

\begin{abstract}
Abstrak: Dalam penelitian ini dilakukan perancangan destilator air laut skala rumah tangga. Destilator yang dirancang terdiri dari yaitu evaporator dan kondenser. Sumber panas untuk evaporator adalah panas dari hasil pembakaran gas LPG. Uap air yang dihasilkan dari evaporator tersebut kemudian dialirkan menuju bagian kondenser melalui bagian dalam pipa tembaga yang berbentuk spiral. Sedangkan di bagian luar pipa kondenser, dialirkan air pendingin dengan bantuan pompa kecil berdaya 12 Watt dengan debit air sebesar 0,169 L/s. Akibat proses pendinginan ini, uap air mengalami kondensasi, yaitu proses perubahan dari fase uap menjadi fase cair berupa air tawar. Penelitian ini merupakan studi awal yang bertujuan untuk mengetahui bagaimana unjuk kerja sistem destilator ini jika ditinjau dari 2 aspek yang meliputi laju produksi air tawar dan kebutuhan energi yang dibutuhkan. Hasil penelitian ini menunjukkan bahwa laju produksi air tawar rata- rata dari sistem ini adalah sebesar 37,69 Liter/hari dan besarnya kebutuhan energi total dari sistem ini adalah sebesar $762,48 \mathrm{kWh} / \mathrm{m}^{3}$.
\end{abstract}

Kata kunci: rancang bangun,destilator, air laut, air tawar. unjuk kerja, laju produksi, kebutuhan energi

Abstract: In this study, the design of household-scale sea water destillator has been done. The destillator consists of an evaporator and a condenser. The heat source for the evaporator is the heat that is generated from LPG combustion. The water vapor that is produced from the evaporator, then flows into the condenser through the inside of a spiral copper pipe. On the outside of the condenser pipe, the cooling water is supplied by a small pump with power of 12 Watt and with the water discharge of $0.169 \mathrm{~L} / \mathrm{s}$. As a result of this cooling process, the condensation occurs i.e the process of changing from the vapor phase to the liquid phase in the form of fresh water. This research is a preliminary study that aims to find out how the performance of this distillator system if it is viewed from two aspects including the rate of fresh water production and energy requirement needed. The result of this study indicates that the average rate of freshwater production from this system is 37.69 liters / day and the total energy requirement of this system is $762.48 \mathrm{kWh} / \mathrm{m}^{3}$.

Keywords: design, destillator, sea water, fresh water, performance, rate of production, energy requirement

\section{PENDAHULUAN}

Ketersediaan air bersih merupakan hal yang sangat penting untuk menunjang aktivitas manusia sehari-hari. Dewasa ini krisis air bersih merupakan masalah yang perlu mendapatkan perhatian serius untuk diselesaikan. Di sisi lain, ketersediaan air laut di muka bumi ini tidak akan ada habisnya. Data dari NASA Earth Laboratory menunjukkan sekitar $71 \%$ wilayah permukaan bumi ditutupi oleh air. Air samudra merupakan sumber air yang dominan yaitu sekitar 96,5\% dari seluruh sumber air di planet bumi [1]. Jika melihat negara Indonesia sendiri yang merupakan negara kepulauan yang terdiri atas 13.466 pulau, penggunaan air laut sebagai sumber air bersih sangat potensial. Data dari Badan Informasi Geospasial (BIG) menunjukkan bahwa negara Indonesia memiliki garis pantai terpanjang urutan kedua setelah Kanada, yakni sepanjang $99.093 \mathrm{~km}$ [2]. Hal ini menunjukkan bahwa pembangun pengolahan air laut menjadi air bersih di daerah pesisir pantai Indonesia merupakan hal yang sangat layak untuk dipertimbangkan dan ditindaklanjuti dengan serius. 
Teknologi proses pemisahan air tawar dan garam salah satuya adalah dengan sistem distilasi. Sistem ini terdiri atas evaporator untuk pendidihan air laut dan kondenser untuk mengembunkan uap air yang dihasilkan. Evaporator yang dirancang menggunakan sumber energi dari pembakaran gas LPG untuk menghasilkan uap air. Uap air yang dihasilkan kemudian dialirkan melalui kondenser. Kondenser yang dirancang terbuat dari pipa spiral tembaga yang digunakan untuk mengalirkan uap untuk kemudian didinginkan dengan aliran air pada bagian luar pipa tembaga. Hasil ouput dari kondenser yang dirancang adalah berupa air bersih. Uap air yang diproduksi dari sistem ini tentu saja lebih banyak jumlahnya jika dibandingkan dengan sistem bak konvensional. Tujuan dari penelitian ini adalah untuk mengetahui bagaimana unjuk kerja sistem destilator skala rumah yang dirancang. Unjuk kerja sistem destilator ini meliputi 2 parameter yaitu laju produksi air air tawar yang dinyatakan dalam satuan debit dan kebutuhan energi yang dibutuhkan persatuan volume air tawar.

\section{METODOLOGI}

Destilator yang dirancang pada penelitian ini terdiri dari 2 bagian yaitu evaporator dan kondenser. Evaporator menggunakan sumber panas dari hasil pembakaran gas LPG. Air laut ditempatkan di dalam wadah evaporator untuk mengalami proses pemanasan hingga mencapai titik didihnya pada suhu sekitar $104^{0} \mathrm{C}$ pada tekanan 1 atm. Pada tahap ini terjadi proses pemisahan antara uap air tawar dan komponen garam yang masih terlarut di dalam air laut yang dipanaskan tersebut.

Gambar 1 menunjukkan diagram alir pada penelitian ini:

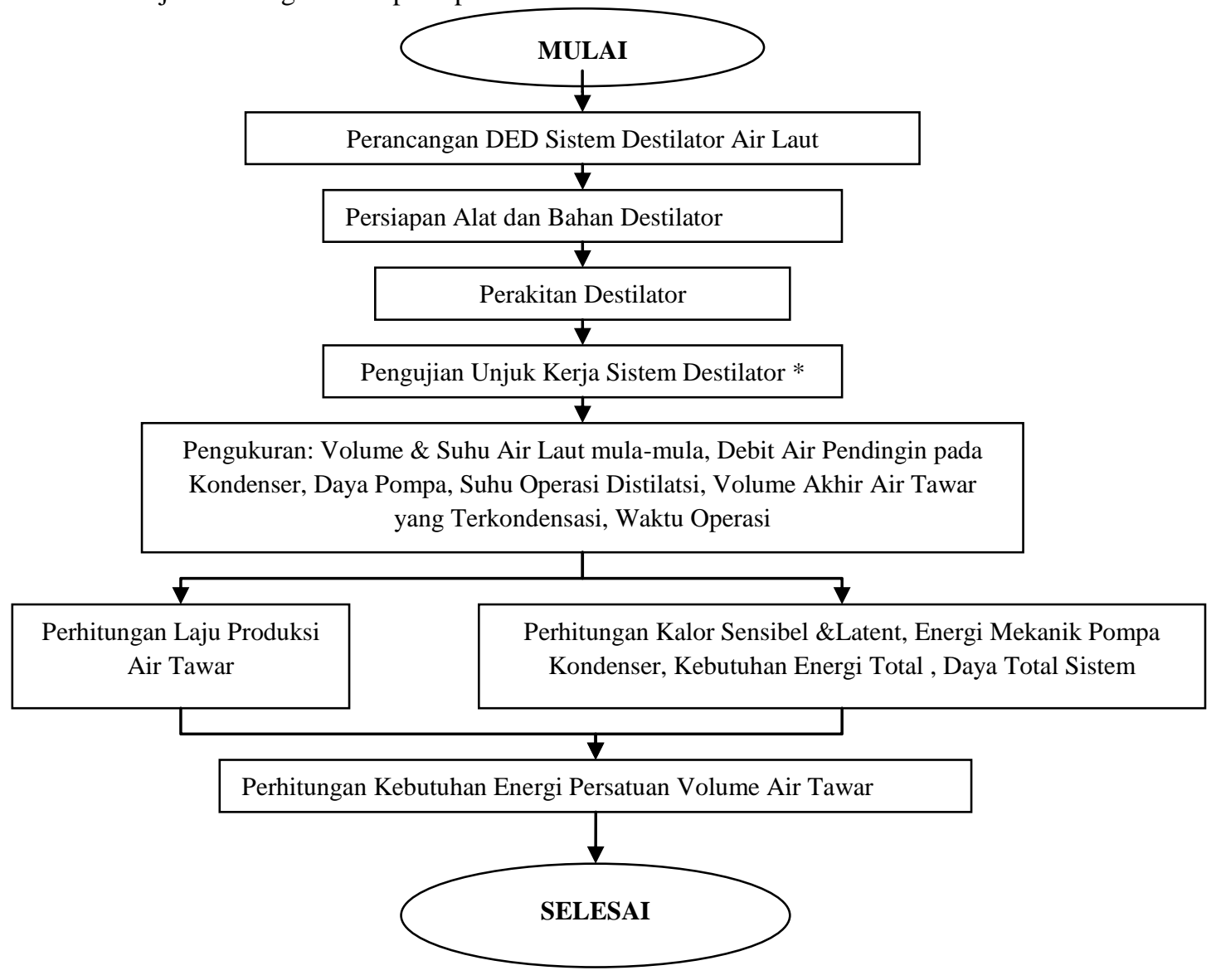

Gambar 1. Diagram Alir Penelitian

Uap air yang dihasilkan dari evaporator tersebut kemudian dialirkan menuju bagian kondenser. Uap air tersebut mengalir melalui bagian dalam pipa tembaga yang berbentuk spiral. Sedangkan di bagian luar pipa kondenser, dialirkan air pendingin dengan bantuan pompa kecil berdaya 12 Watt. Debit air pendingin yang 
digunakan dalam penelitian ini adalah sebesar 0,169 L/s. Pada bagian kondenser ini terjadi fenomena perpindahan panas dari aliran uap air ke aliran air pendingin. Dengan kata lain uap air mengalami pendinginan. Akibat proses pendinginan ini, uap air mengalami kondensasi, yaitu proses perubahan dari fase uap menjadi fase cair. Dengan demikian hasil keluaran dari bagian kondenser adalah merupakan air tawar yang merupakan produk dari sistem destilator ini.

Gambar 2 menunjukkan foto sistem destilator yang dirancang pada penelitian ini

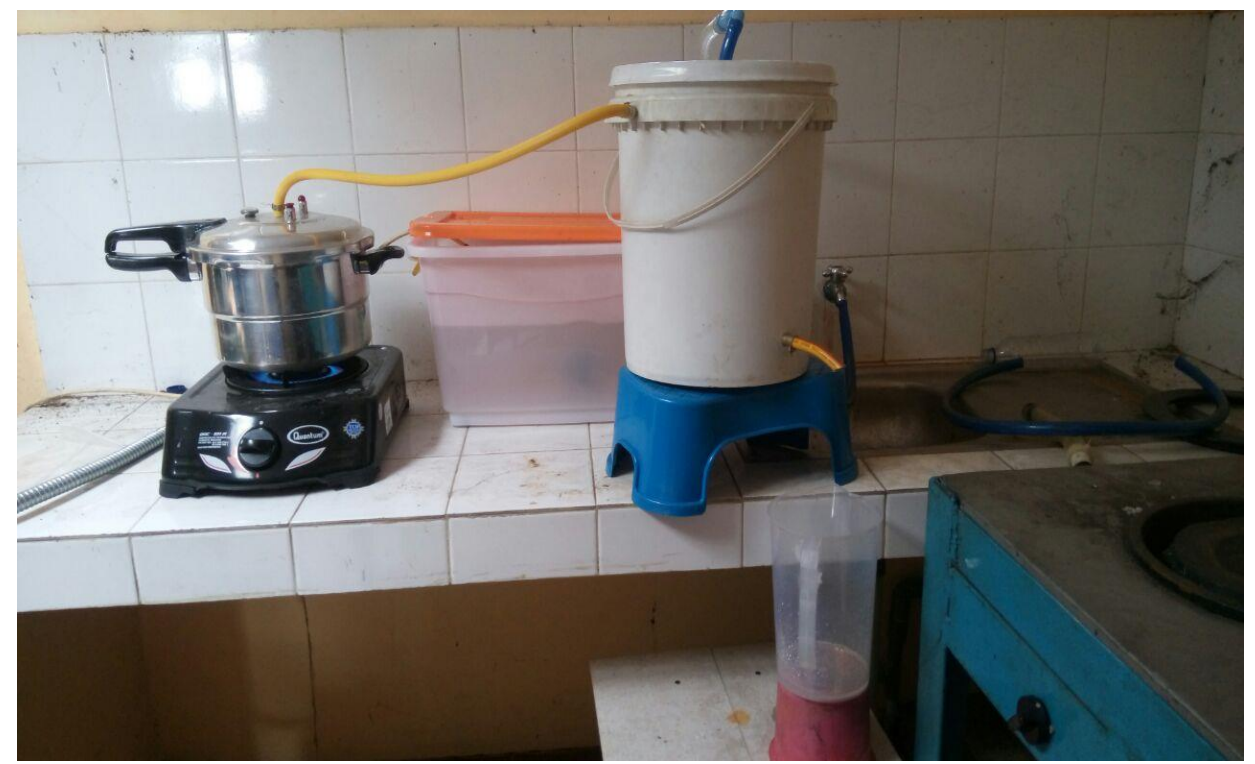

Gambar 2. Sistem Destilator

\section{HASIL DAN PEMBAHASAN}

\section{A. Perhitungan Laju Produksi Air Tawar}

Pengujian pertama menggunakan air laut dengan volume awal 1 Liter dengan suhu awal yaitu $30,9{ }^{0} \mathrm{C}$. Suhu operasi distilasi pada bagian evaporator adalah $104^{\circ} \mathrm{C}$ dengan waktu operasi 22 menit 29 detik. Dari proses tersebut dihasilkan volume air tawar hasil distilasi sebanyak $600 \mathrm{~mL}$. Sementara debit air pendingin pada bagian kondenser adalah sebesar 0,169 L/s. Dari data tersebut dapat dihitung kecepatan produksi air tawar pada pengujian pertama adalah:

$$
\dot{V}_{w 1}=\frac{600 m L}{\left(22+\frac{29}{60}\right) \text { menit }}=\frac{0,6 L}{22,48 m e n i t}=0,027 \mathrm{~L} / \text { menit }=1,601 \mathrm{~L} / \mathrm{jam}=38,43 \mathrm{~L} / \mathrm{han}
$$

Pengujian kedua menggunakan air laut dengan volume air laut awal 2 Liter dengan suhu awal yaitu $29^{0} \mathrm{C}$. Suhu operasi distilasi pada bagian evaporator adalah $104^{\circ} \mathrm{C}$ dengan waktu operasi 50 menit 40 detik. Dari proses tersebut dihasilkan volume air tawar hasil distilasi sebanyak $1300 \mathrm{~mL}$. Sementara debit air pendingin pada bagian kondenser adalah sebesar $0,169 \mathrm{~L} / \mathrm{s}$.

Dari data tersebut dapat dihitung kecepatan produksi air tawar pada pengujian kedua sebagai berikut: 


$$
\dot{V}_{w 2}=\frac{1300 \mathrm{~mL}}{\left(50+\frac{40}{60}\right) \text { menit }}=\frac{1,3 \mathrm{~L}}{50,67 \text { menit }}=0,026 \mathrm{~L} / \mathrm{menit}=1,539 \mathrm{~L} / \mathrm{jam}=36,94 \mathrm{~L} / \mathrm{hari}
$$

Dengan demikian laju produksi air tawar rata-rata air tawar dapat dihitung sebagai berikut:

$$
\dot{V}_{w}=\frac{\dot{V}_{w 1}+\dot{V}_{w 2}}{2}=\frac{38,43+38,95}{2} \mathrm{~L} / \text { hari }=37,69 \mathrm{~L} / \text { hari }
$$

\section{B. Perhitungan Energi Thermal}

Perhitungan energi thermal pada sistem destilator air laut ini dilakukan dengan menghitung kalor sensibel dan kalor latent yang digunakan untuk menguapakan air laut.

$$
\begin{aligned}
& \text { Massa air laut pada pengujian pertama dapat ditentukan dengan } \\
& m_{s w 1}=\rho_{s w} . V_{s w 1}=1030 \mathrm{~kg} / \mathrm{m}^{3} \cdot 10^{-3} \mathrm{~m}^{3}=1,03 \mathrm{~kg}, \quad \text { dimana massa jenis air laut adalah } \\
& \rho_{s w}=1030 \mathrm{~kg} / \mathrm{m}^{3} \text { dan volume air laut yang diujicoba adalah } V_{s w 1}=1 L=10^{-3} \mathrm{~m}^{3} \text {. }
\end{aligned}
$$

Dengan mensubstitusikan nilai suhu awal $30,9{ }^{0} \mathrm{C}$ dan suhu boiling point $104{ }^{0} \mathrm{C}$ di bagian evaporator, dan Kalor jenis air laut $c p_{s w}$ sebesar $3,9 \mathrm{~kJ} / \mathrm{kg}^{0}{ }^{0} \mathrm{C}$ maka kalor sensibel yang dibutuhkan pada pengujian pertama dapat dihitung yakni sebagai berikut:

$$
Q_{s 1}=1,03 \mathrm{~kg} \cdot 3,9 \mathrm{~kJ} / \mathrm{kg} \cdot{ }^{0} \mathrm{C} .\left(104^{0} \mathrm{C}-30,9^{0} \mathrm{C}\right)=293,64 \mathrm{~kJ}
$$

Massa air tawar yang terdistilasi pada pengujian pertama dapat dihitung dengan $m_{w 1}=\rho_{w} \cdot V_{w 1}=998 \mathrm{~kg} / \mathrm{m}^{3} \cdot 0,6 \cdot 10^{-3} \mathrm{~m}^{3}=0,599 \mathrm{~kg}$, dimana massa jenis air adalah $\rho_{w}=998 \mathrm{~kg} / \mathrm{m}^{3} \mathrm{dan}$ volume air tawar yang terdistilasi adalah $. V_{w 1}=600 m L=0,6.10^{-3} \mathrm{~m}^{3}$.

Dengan demikian kalor latent yang diperlukan untuk mengubah fase air uap air yang mendidih dari fase cair jenuh menjadi uap jenuh pada pengujian pertama dapat dihitung dengan $Q_{l t 1}=m_{w 1} \cdot\left(h_{g w}-h_{l w}\right)$ $=0,599 \mathrm{~kg} \cdot(2681,96-436,50) \mathrm{kJ} / \mathrm{kg}=1344,58 \mathrm{~kJ}$, dimana enthalpi air pada fase uap jenuh adalah $h_{g w}=2681,96 \mathrm{~kJ} / \mathrm{kg}$ dan enthalpi air pada fase cair jenuh adalah $h_{g w}=436,50 \mathrm{~kJ} / \mathrm{kg}$

Sehingga energi thermal total yang diperlukan pada pengujian pertama ini adalah: $Q_{\text {total } 1}=Q_{s 1}+Q_{l t 1}=293,64 k J+1344,58 k J=1638,22 k J$.

Dengan konsep perhitungan yang sama dengan pengujian pertama, massa air laut pada pengujian kedua dapat ditentukan dengan $m_{s w 2}=\rho_{s w} . V_{s w 2}=1030 \mathrm{~kg} / \mathrm{m}^{3} \cdot 2.10^{-3} \mathrm{~m}^{3}=2,06 \mathrm{~kg}$, dimana massa jenis air laut adalah $\rho_{s w}=1030 \mathrm{~kg} / \mathrm{m}^{3}$ dan volume air laut yang diujicoba adalah $V_{s w 2}=2 L=2.10^{-3} \mathrm{~m}^{3}$.

Dengan mensubstitusikan nilai suhu awal $29{ }^{\circ} \mathrm{C}$ dan suhu boiling point $104{ }^{0} \mathrm{C}$ di bagian evaporator, dan Kalor jenis air laut $c p_{s w}$ sebesar $3,9 \mathrm{~kJ} / \mathrm{kg} .{ }^{0} \mathrm{C}$ maka kalor sensibel yang dibutuhkan pada pengujian kedua dapat dihitung yakni sebagai berikut:

$$
Q_{s 2}=2,06 \mathrm{~kg} \cdot 3,9 \mathrm{~kJ} / \mathrm{kg} \cdot{ }^{0} \mathrm{C} \cdot\left(104^{0} \mathrm{C}-29^{0} \mathrm{C}\right)=602,55 \mathrm{~kJ}
$$


Joko Setiyono, dkk, Rancang Bangun Destilator Air Laut Skala Rumah Tangga...,

Massa air tawar yang terdistilasi pada pengujian kedua dapat dihitung dengan $m_{w 2}=\rho_{w} \cdot V_{w 2}=998 \mathrm{~kg} / \mathrm{m}^{3} \cdot 1,3 \cdot 10^{-3} \mathrm{~m}^{3}=1,297 \mathrm{~kg}$, dimana massa jenis air adalah $\rho_{w}=998 \mathrm{~kg} / \mathrm{m}^{3} \mathrm{dan}$ volume air tawar yang terdistilasi pada pengujian kedua adalah $V_{w 2}=1300 \mathrm{~mL}=1,3 \cdot 10^{-3} \mathrm{~m}^{3}$.

Dengan demikian kalor latent yang diperlukan untuk mengubah fase air uap air yang mendidih dari fase cair jenuh menjadi uap jenuh pada pengujian kedua dapat dihitung dengan $Q_{l t 2}=m_{w 2} \cdot\left(h_{g w}-h_{l w}\right)$ $=1,297 \mathrm{~kg} .(2681,96-436,50) \mathrm{kJ} / \mathrm{kg}=2913,26 \mathrm{~kJ}$, dimana enthalpi air pada fase uap jenuh adalah $h_{g w}=2681,96 \mathrm{~kJ} / \mathrm{kg}$ dan enthalpi air pada fase cair jenuh adalah $h_{g w}=436,50 \mathrm{~kJ} / \mathrm{kg}$

Sehingga energi thermal total yang diperlukan pada pengujian kedua ini adalah $Q_{\text {total } 2}=Q_{s 2}+Q_{l t 2}=602,55 k J+2913,26 k J=3515,81 k J$.

\section{C.Perhitungan Kebutuhan Energi Total Per Satuan Volume Air Tawar}

Sistem ini membutuhkan bantuan pendinginan dimana air pendingin dialirkan secara kontinu dengan bantuan pompa yang memiliki daya 12 Watt. Jika pada pengujian pertama pengoperasian dilaksanakan selama 22 menit 29 detik, maka energi mekanik pompa (W) yang digunakan sistem ini pada pengujian pertama adalah $W_{1}=12$ Watt. $(22.60+29)$ sekon $=16,19 \mathrm{~kJ}$. Dengan demikian kebutuhan energi total yang dibutuhkan sistem destilator pada pengujian pertama ini adalah ini adalah $E_{\text {total } 1}=Q_{\text {total } 1}+W_{1}=1638,22 \mathrm{~kJ}+16,19 \mathrm{~kJ}$ $=1654,41 \mathrm{~kJ}$. Sedangkan daya yang diperlukan pada pengujian pertama ini adalah $P_{1}=\frac{E_{\text {total } 1_{1}}}{t_{\text {operasi }_{1}}}=\frac{1654,41 \mathrm{~kJ}}{1349 \text { sekon }}=1,23 \mathrm{kWatt}$.

Sedangkan pada pengujian kedua pengoperasian dilaksanakan selama 50 menit 40 detik. Dengan demikian energi mekanik pompa yang digunakan pada sistem ini adalah $W_{2}=12$ Watt. $(50.60+40)$ sekon $=36,48 k J$. Dengan demikian kebutuhan energi total pada sistem destilator pada pengujian kedua ini adalah $E_{\text {total } 2}=Q_{\text {total } 2}+W_{\text {pump } 2}=3515,81 k J+36,48 k J=3552,29 k J$. Kemudian, daya yang diperlukan pada pengujian kedua ini adalah: $P_{2}=\frac{E_{\text {total } 2}}{t_{\text {operasi } 2}}=\frac{3552,29 \mathrm{~kJ}}{3040 \mathrm{sekon}}=1,17 \mathrm{kWatt}$

Perhitungan kebutuhan energi total persatuan volume air tawar (EPV) pada pengujian pertama adalah sebesar $E P V_{1}=\frac{P_{1}}{\dot{V}_{w 1}}=\frac{1,23 \mathrm{~kW}}{4,44.10^{-4} \mathrm{~L} / \mathrm{s}}=2757 \mathrm{~kJ} / \mathrm{L}=765,93 \mathrm{kWh} / \mathrm{m}^{3}$

Sedangkan perhitungan kebutuhan energi total persatuan volume air tawar (EPV) pada pengujian kedua adalah sebesar $E P V_{2}=\frac{P_{2}}{V_{w 2}}=\frac{1,17 \mathrm{~kW}}{4,28.10^{-4} \mathrm{~L} / \mathrm{s}}=2732 \mathrm{~kJ} / \mathrm{L}=759,04 \mathrm{kWh} / \mathrm{m}^{3}$

Dengan demikian kebutuhan energi total persatuan volume air tawar rata-rata dapat dihitung sebagai berikut:

$$
E P V=\frac{E P V_{1}+E P V_{2}}{2}=\frac{765,93+759,04}{2} \mathrm{kWh} / \mathrm{m}^{3}=762,48 \mathrm{kWh} / \mathrm{m}^{3}
$$




\section{KESIMPULAN}

Dari hasil penelitian ini dapat ditarik kesimpulan sebagai berikut:

1. Pengujian sistem destilator skala rumah tangga ini menggunakan sumber energi pembakaran gas LPG dan pompa listrik kecil dengan daya sebesar 12 Watt untuk mengalirkan air pendingin dengan debit sebesar $0,169 \mathrm{~L} / \mathrm{s}$

2. Pengujian dilakukan sebanyak 2 kali dengan feed air laut masing masing sebanyak 1 Liter dan 2 Liter dalam jangka waktu masing-masing 22 menirt 29 detik dan 50 menit 40 detik.

3. Hasil perhitungan laju produksi air tawar pada pengujian pertama dan kedua berturut turut adalah sebesar 38,43L/hari dan 36,94 L/hari dengan laju produksi air tawar rata-rata sebesar 37,69 Liter/hari.

4. Hasil perhitungan kebutuhan energi total dari sistem ini yang meliputi energi termal dan energi mekanik pada pengujian pertama dan kedua berturut turut adalah sebesar $765,93 \mathrm{kWh} / \mathrm{m}^{3}$ dan $759,04 \mathrm{kWh} / \mathrm{m}^{3}$, sehingga dapat dikatakan memiliki nilai rata-rata sebesar $762,48 \mathrm{kWh} / \mathrm{m}^{3}$.

\section{DAFTAR PUSTAKA}

1. http://water.usgs.gov/edu/watercycleoceans.html

2. http://nationalgeographic.co.id/berita/2013/10.html

3. http://www.kelair.bppt.go.id/Sitpa/Artikel/Ro/ro.html

4. J.P. Holman, Heat Transfer, Mc Graw-Hill, New York, U.S.A, 1986.

5. Incropera, Frank.P, 1985, Fundamentals of Heat Transfer and Mass Tansfer, Second Edition, John Willey \&Sons, New York

6. Arora, C.P., 1998, Thermodynamics, Mc Graw-Hill Publishing Company, New York 